\title{
Self-Dialogue as a Fundamental PROCESS OF EXPRESSION
}

\author{
VICTOR N. SHAW \\ California State University, Nortbridge
}

\begin{abstract}
Self-dialogue involves a constant process of demarcation and interaction betreeen "I" and "me," between the speakable and the unspeakable, and between what is said and what is meant. This paper studies self-dialogue in its main aspects. First, it reviews relevant contributions in the existing literature. Second, it attempts a working definition of selfdialogue. Third, it examines self-dialogue werth regard to its main dimensions and processes. Fourth, it identifies rules that guideself-dialogue. Fifth, it looks intopractical applications and implications of self-dialogue in life and personal management. The major findings and arguments are: Self-dialogue is a fundamental process of expression; it mediates between self-image and social experience; it is regulated by ontological limits, cultural norms, and social rules; and it serves as an adaptive mechanism for self-presentation, identity acquisition, stress management, health maintenance, and personal integration.
\end{abstract}

\section{SELF-DIALOGUE AS A FUNDAMENTAL PROCESS OF EXPRESSION}

Human beings are self-conscious and self-monitoring organisms. They see and evaluate what they think and what they do. They collect information on themselves and incorporate feedback from the past into their future thoughts and acts.

Self-dialogue builds upon the self-conscious nature of human beings. It distinguishes things from one another in the consciousness and establishes meaningful connections among them according to their occurrence in time, across space, as well as in relation to the self. Selfdialogue makes sense out of the consciousness. It is an organizing theme or force of the human mental process. 
This paper studies self-dialogue as a fundamental process of expression in contemporary life. It first reviews relevant contributions in the existing literature. It then attempts a working definition of self-dialogue. Third, it examines self-dialogue in its main dimensions and processes. Fourth, it identifies rules that guide self-dialogue. Fifth, it looks into practical applications and implications of self-dialogue in life and personal management. The main findings and arguments are: Self-dialogue is a fundamental process of expression; it mediates between self-image and social experience; it is regulated by ontological limits, cultural norms, and social rules; and it serves as an adaptive mechanism for self-presentation, identity acquisition, stress management, health maintenance, and personal integration.

\section{SOURCES OF INSPIRATION}

Self-dialogue is as old as the human existence. It remains unnoticed for a long time until philosophers recognize the distinction of mind from body and thoughts from acts. After centuries of philosophical contemplation and speculation, it comes to the era of positive science (Sarton 1952; Comte 1970; Cooper 1996). In science, while neurologists study the function of brain, psychologists the process of mind, and sociologists the link of individual efforts to social reality, self-dialogue seems yet to be identified and scrutinized as an important subject of research.

From a purely linguistic point of view, dialogue involves two separable identities or parties in a communicative interaction. For self-dialogue to take place, it requires that the self divide into relatively independent entities with each taking a relatively different perspective. The requirement leads to some fundamental questions about the self and self-dialogue: What is the self? How does the self take on multiple identities and assume different perspectives? What process does selfdialogue involve? What is said in self-dialogue? And how does selfdialogue relate to the self, others, and social experience?
In psychology, references fall under three theoretical frameworks. Psychoanalysis views the self as a constant striving to reduce tension generated by two innate drives: the urge to live and the urge to die. Composed of id, ego, and superego, the self operates on three different principles: pleasure, reality, and morality (Freud 1962). On the principle of pleasure, id seeks to satisfy the self of its innate needs: hunger, thirst, and sex. By the principle of morality, superego sets goals and establishes standards for the self. In reality, ego mobilizes and manipulates ways and means to deal with pressures from id, superego, and external environments on behalf of the self. Behaviorism defines the self as "an organized system of responses" (Skinner 1953:285). Although it distinguishes stimuli from one another, the self remains essentially in the dark as a black box to behaviorists. Phenomenology sees the self as a phenomenal field in which one relates to other people, things, and entities (Rogers 1959). The self develops images about what one is and what one would like to be. It is a force for both growth and existential alienation.

Sociological contributions come from three theoretical perspectives as well. Functionalism considers the self and its needdispositions as determined largely by the dominant patterns of value orientations in culture and society (Parsons and Shils 1951). As such, it is meaningful to talk about national characters, such as the classical "particularism-achievement" Chinese ethos and the modern "other-directed" American character (Riesman 1950). Conflict theory equalizes the self to the consciousness of one's class, race, gender, status, and other vital social interests (Marx and Engels 1958). The marginal man, a cultural or racial hybrid who is on the margins of two cultures and two societies, is likely to experience double consciousness/attitudinal ambivalence, moody/temperamental conducts, superiority/achievement complex, and intermediary/leadership roles in his selfhood (Park 1928; Stonequist 1937). Symbolic interactionism characterizes the self as an agent for subjective meaning, interpretation, and symbolic interaction (Blumer 1969). The self develops through a role-taking process, which proceeds from the play stage, to the 
game stage, and to the generalized other stage (Mead 1934). At the stage of generalized others, the self internalizes the general attitude of one's community, becomes an object to itself, and therefore is able to engage in various role-playing activities in accordance with one's self-image as well as different social expectations.

From the recent debate on modernity, the self emerges in two contrasting discourses, models, and pursuits. Modernists pursue a self of calculation, rationality, uniformity, outwardly expression, objectification, effectiveness, and efficiency. Seeing both exciting opportunity and threatening risk in the industrial social order, they attempt a balance within the self between security and risk, between opportunity and danger. On the other hand, postmodernists claim to have discovered a self of ambivalence, ambiguity, diversity, multiplicity, plurality, subjectivity, and variability. Realizing that contemporary social and cultural reality cannot be rationally and uniformly ordered and controlled, they charge the self to the liberation of differences, the proliferation of discourses, and the development of rationalities through ethnic, religious, sexual, cultural, architectural, aesthetic, and other local entities or identities (Fox 1994; Bertens 1995).

At the systemic level, a conceptualization about the self needs to reconcile its existence in singularity with its presentation in multiplicity. Regarding the multiplicity of the self, William James (1890) noted that the empirical self has three constituents: the material, the social, and the spiritual. He further specified that the social self has as many selves as there are others who respond to them. Riesman (1950) argued that modern man behaves very much like a chameleon in conforming to the variable external demands in his highly specialized environment. Goffman (1959) found that people need to deliberately and variably use self-presentations to manipulate others due to the ever-changing situational requirements. Gordon and Gergen suggested that "it is much more fruitful to speak of multiple conceptions" of the self because individual behavior is often inconsistent and highly variable from situation to situation (1968:20). Specifically, as put by Stryker, the self is "a wondrously differentiated and complex congeries of a vast variety of elements - differentiated processes like selfconsciousness, self-awareness, self-presentation; differentiated characteristics like self-control, self-confidence, self-esteem; differentiated content like academic self-conception, spousal selfconcept, age-graded self concepts; differentiated traits like liberal, generous, compulsive; differentiated temporal and normative referents like real self, extant self, ideal self, future self, desired self, possible self" (1989:42).

While being in multiple presentations, roles, and statuses, the self lodges by itself in one's single, whole body, mind, and existence. Mead (1934) saw a "complete self" that reflects the unity of the social process and further the single universe of discourse about all humanity. Allport (1937), Lecky (1945), Fromm (1947), and Rogers (1951) all observed that people develop and experience a continuing identity, a consistent self, in their life. Parsons (1951) likened the self to society as a unitary, highly organized system. Rosenberg (1979) coined the concept of global self and characterized the global self as the totality of one's thoughts and feelings having reference to oneself as an object. More recently, attempts are made to see how multiple identity elements are organized by prominence and preferential ordering into a single, whole integrated self-identity hierarchy (Hoelter 1983; Stryker 1989; Stapleton 2000; Sokefeld 2001).

Regarding the nature of content in self-dialogue, the Bakhtin circle traced the transitions in linguistic expressions from "social intercourse" to "outer speech" to "inner speech" to consciousness. They claimed that self-observation, communication within the self, "the understanding of one's own inner sign," or one's inner speech is itself the product of one's entire social life (Volosinov 1973). According to the Bakhtin circle, dialogue has two distinct senses. In the first sense, dialogue involves real and potential audiences, earlier and possible later utterances, habits and "genres" of speech and writing, and other complex social factors. It addresses an "already spoken about" world and acts upon a socially constituted "field of 
answerability." In the second sense, dialogue corresponds to "monologue" as its opposite and represents a particular discursive stance of speakers. It faces an unforeseen and "unfinalizable" world of possibilities but nonetheless gears toward the readiness for something new and original. As put by Bakhtin himself, "nothing conclusive has yet taken place in the world, the ultimate word of the world and about the world has not yet been spoken, the world is open and free, everything is still in the future and will always be in the future" (1984:166). In both senses, dialogue can take place within one's own mental domain as inner-speech or self-dialogue although it is essentially social in content. As a matter of fact, the Bakhtin circle was even inclined to emphasize the therapeutic effect of dialogue in verbalizing hidden mental complexes and credit Freud for his attention to the role of language in psychoanalysis (Volosinov 1987). In the social construction dimension, a recent development from the Bakhtin circle and its dialogism is the dialogic approach to the talk and back talk of collective action (Steinberg 1999).

In current research, narrative analysis has emerged as both an important epistemological approach and a critical methodological technique to the study of self-narratives or self-dialogue-based materials, such as diaries, letters, autobiographies, and other personal documents. On the one hand, narrative analysis explores why selfnarratives are constructed as they are (Somers 1994; Somers and Gibson 1994). With regard to the self in particular, it examines how mind assumes its principal function of world making amid the creation of stories or narratives (Bruner 1987), how the self plays out as a narrative or story rather than a being or thing (Polkinghorne and Bamberg 1991; Bamberg 1997), how self-identity is achieved through use of the past in the present (Bielby and Kully 1989), and how life unfolds and continues in the temporal and dramatic production of self-narratives (Bruner 1987; Polkinghorne and Bamberg 1991). On the other hand, narrative analysis provides specific methods and techniques for acquiring and utilizing narrative data in disciplinary and interdisciplinary inquires (Riessman 1993). In the concrete, it describes and explains what areas and issues a researcher needs to attend to when he or she searches for narrative information, how he or she dissects a narrative to understand the lived experience of the narrator, and what steps he or she may take to translate tales and life stories into usable research.

Empirical research using self-narratives abounds. Hermans (1993) conducts an idiographic study on two women with long-term imaginal figures. Viewing self-narratives as polyphonic novels, he observes two types of self-investigations: one from the familiar "I" perspective and the other from the imaginal "other I" position. Scheff (1995) analyzes self-defense against verbal aggression. Projecting the inner mental process into a private dialogue, he elaborates how one ignores aggression while managing his or her anger, shame, and social bonds. Ford (1996) studies the process of adopting an appropriate perspective in a multicultural classroom. Witnessing how individuals deconstruct their socialization experience as belonging to a particular race or ethnicity and come to understand the symbolic meanings of past events, he argues that the deconstructive process involves dialogues between the acting and reflexive self and between the self and others. In other applications, Ewick and Silbey (1995) examine narrative stories and tales expressive of hegemony, subversion, and resistance. Seale (1995) explores the development of meaningful narratives of the self in the face of death. Lichtenstein and Baruch (1996) investigate the construction of the adoption self-narrative by three of its components, the birth, the placement, and the adoption stories. Riches and Dawson (1996) evaluate the reordering of parental narratives in the aftermath of a child's death and its impact on parental self-identity and marital relationships. Polletta (1998) discusses the role of narratives in social movements. Finally, Nichols (2000) attends to multivocality or narratives in public domains in his proposed dialogical constructionist approach or discourse to social problems.

In a more thematic scheme, researchers on metacognition identify self-talk as key to both knowing the characteristics, constraints, parameters, and demands of a particular social task and knowing how to proceed to focus, follow through, and finish a specific task 
(Manning 1990). Metacognition refers to knowledge about thinking, mental experiences about thinking, or "cognitions about cognitive, affective, perceptual, and motor human characteristics" (Flavell 1987:21). According to Helmstetter, what we say to ourselves determines our success at everything we attempt. He defines self-talk as "a way to override our past negative programming by erasing or replacing it with conscious, positive new-directions" (1986:59) and classifies self-talk into five levels. Level I self-talk features negative acceptance: "I can't" or "If only I could." It is the least beneficial. Level V self-talk represents universal affirmation: "It is." It is the most beneficial. In between are Level II self-talk - recognition of the need to change: "I need to" or "I should"; Level III self-talk decision to change: "I never" or "I no longer"; and Level IV self-talk - the better you: "I am."

Following a similar line of analysis, Butler (1992) finds that people often invoke overbearing judges rather than realistic guides in their self-talk. She identifies three types of judges: drivers who relentlessly and unrealistically push us to "get busy" or "do it right"; stoppers who limit us with "no," "don't," or "only if" and keep us from effectively expressing and asserting ourselves; and confusers who distort our reality and mislead us to defective or irrational thinking. Given the fact that we drive, stop, and confuse ourselves, we need to take five steps in our self-talk. First is awareness: listen to what we are talking to ourselves. Second is evaluation: ask if our self-talk is helpful. Third is identification: determine what driver, stopper, or confuser is maintaining in our inner speech. Fourth is self-support: replace unhelpful judges with permitters. The last step is self-guidance: decide what action will fit with our more helpful way of talking to ourselves (Butler 1992; Manning and Payne 1995).

\section{A WORKING DEFINITION}

It is unrealistic to expect a comprehensive understanding of selfdialogue before a broad and in-depth examination of its main aspects. On the other hand, a meaningful analysis requires some positive identification of the concept: what it is and how it relates to mind and body. A working definition is therefore in order.

Drawing from various sources of inspiration in the literature, it is obvious that self-dialogue is a conversation among different identity elements or perspectives within oneself. It occurs out of an innate quality of human beings. In form, self-dialogue involves both verbal utterance and unspoken yet verbalizable image, intent, and feelings. In content, it contains information about one's idealized state of affairs, perceived image of reality, and intended scheme of action, as well as intercommunications between and among those mental domains of mind. It also includes descriptions of one's social experience, expressions of one's inner world, and communicative connections between one's body and mind, actions and thoughts, social actualization and ego-ideals.

Inherent in the working definition are three basic questions. First, can one talk to oneself in different perspectives? In commonsense life, when one says: "I need to be alone with myself for a while" or "I need to sort it out by myself," it actually means that one needs to talk to oneself and think through a situation. In religious practice, when people meditate and pray with God, it actually means that they engage in a dialogue with an assumed entity in their mind. As the assumed entity is within themselves, their dialogue with God turns into selfdialogue in the final analysis. In psychology, when intrapersonal communication is defined as "that communication which occurs within the individual” (Barker and Kibler 1971:4), it essentially suggests that self-dialogue be explored as an area of inquiry in contrast to the well-studied field of interpersonal communications. Obviously, selfdialogue manifests in different fields of life and inquiry. It is a takenfor-granted process in human mind.

Second, how does self-dialogue occur? It occurs in consciousness when one thinks toward oneself, examining one's own ability, rationality, morality, and whole existence or figuring out strategies and tactics in one's relationship with others. Self-dialogue is part 
of human thinking process but differs from the latter in that it centers on oneself: "Am I able to do it?"; "Why did I do it?"; "Am I right to do it?"; "Who am I?"; or "What would I do if I were in that position?" Generally, thinking, association, and imagination take place because human beings are self-conscious; consciousness serves as a viewing board, a screen, or a mental field for the self; and the self possesses the quality and ability to reflect things upon and project ideas into consciousness. Specifically, self-dialogue occurs because the self is able to project itself as a seemingly objective entity on the reflective background of mind and interact with the so-produced entity or image as if it is another thing or existence.

Third, what occurs in self-dialogue? It depends upon individuals and their specific experience. Different people have different things to talk to themselves. A particular person may conduct different selfdialogues at different ages, in different positions, and even at different moments. But generally, self-dialogue falls into four main categories in content: self-explanation, self-consolation, self-rehearsing, and selfevaluation. Self-explanation is to explain an act or a situation when it is in self-quandary: "Why did I do it or how did it happen to me?" Self-consolation is to reconcile inner conscience with outer behavior for the sake of peace in mind: "I am sorry for what I did but I was compelled by the circumstance." Self-rehearsing is to prepare for a social role-playing activity: "Am I able to do it in a better way?" Finally, self-evaluation is to maintain self-image, self-identity, and self-esteem: "Where do I stand?"

In simple terms, self-dialogue refers to one talking to oneself. Taken for granted in different fields of life and inquiry, it occurs amid the normal thinking process due to the self-reflection and self-projection quality of human mind. Self-dialogue varies in content from experience to experience and from time to time. It, however, serves people for various purposes in all their experiences at all time.

\section{MAIN DIMENSIONS AND PROCESSES}

Self-dialogue builds upon the demarcation and interaction among various identity elements within the self as well as between the self and the environment. To understand self-dialogue, it is necessary to examine how the self divides within itself and how it relates to the larger social context.

\section{Between "I" and "Me"}

The distinction between "I" and "me" was first made by Mead (1934). According to him, "the self is essentially a social process" going on with "two distinguishable phases" (Mead 1934:178). One phase is "I," the unorganized response of the organism to the attitudes of others. The other is "me," a set of organized perspectives one has learned from others on oneself. In the "I" phase, the individual maintains a sense of freedom, innovation, and creativity. In the "me" phase, the individual brings the influence of others into consciousness and remains duty-bound to social responsibility.

Self-dialogue is essentially a conversation between "I" and "me." "I" gives order, command, and direction but needs to be informed, advised, and responded by "me." "I" expresses desires, feelings, and sentiments but needs to be understood, comforted, and confirmed by "me." For instance, in a technical staffer's self-dialogue on how to respond to a supervisor's order, "I" may set such standards as being timely, professional, and competent. "Me" may provide information on the supervisor, the order received, and the resources available to carry out the order. Various options are then developed. A particular choice may be made in the end as "I" and "me" talk to each other back and forth throughout the decision-making process. Similarly, in a bureaucrat's self-dialogue on how to cope with a failure in promotion, "I" may express disappointment, frustration, and anger. "Me" may present information on the policies and procedures of promotion as well as about the people who have failed and succeeded in promotion. With the information, " $\mathrm{I}$ " is then able to put itself in proper 
perspective, avoiding excessive self-condemnation and moving ahead to explore alternative avenues for success.

Negotiation and compromise are obviously involved in the interaction between "I" and "me." "I" may back down from its demands due to the power of the information presented by "me." "Me" may change its strategies in supplying information, making suggestions, and coping with stress according to the mood and determination of "I." In the case of a technical staffer's responding to a supervisor's order, "I" may excuse itself from the previously set standard of performance if "me" advises that the supervisor is under pressure to step down or it is not cost-beneficial to impress the supervisor with an exceptional performance. Likewise, in the case of a bureaucrat's reacting to failure in promotion, "me" may allude to the injustice in the promotion procedure and advise "I" to fight for itself if "I" feels strong about its qualifications and deservedness.

While they are relatively separate entities, "I" and "me" are essentially the two sides of the coin, the self. They go hand in hand and reinforce each other for the ultimate interest of the self.

\section{Between the Whole Self-Existence and Fragmented Social Experience}

Individual social experiences are always limited to particular people and things in particular time and locations. The meaning of a particular experience is not always clear within its original social context. A socially acting individual needs to place each episode of his or her experience on the reflective background of consciousness and evaluate its importance in relation to his or her whole self-existence. In a sense, individual social experiences are fragmented, compartmentalized, and scattered in pieces. It is the self that organizes pieces of social experience into a system of reality and develops an image of the world from particularity to generality and from specificity to universality.
Self-dialogue bridges fragmented social experience with the whole self-existence. Before a social encounter, self-dialogue deducts specific expectations, strategies, and guidelines from the general system of self-experience and makes the self prepared. Suppose a construction subcontractor is arranged to meet a real estate contract manager. The subcontractor may talk to him-or herself and decide where to position the meeting in his or her overall business endeavor, which in turn is only a part of his or her whole life commitment. Once the positioning is determined, he or she can develop various specific strategies to shape the upcoming meeting to his or her business advantage.

After a social encounter, self-dialogue inducts general feelings, impressions, and attitudes from pieces of concrete interaction and assigns the whole event some meaning or value in the overall system of self-experience. Suppose a project director is scheduled to see the principal investigator in a funded project. After the meeting, the project director may ask him- or herself: "Did the meeting go well? Did I do what I was supposed to do? Was the principal investigator trustworthy in what he or she promised? Was he or she demanding on what he or she expected? Have the project objectives been achieved for the last period of time? Was the meeting productive? Was it just another business-as-usual event?" After a series of questions and answers through self-dialogue, the meeting as an individual event can be entered, with a specific value of importance, into the whole system of self-experience for future reference.

During a social encounter, self-dialogue may also be activated to retrieve information and customize response in simultaneity with action. Suppose one is having a meeting with one's prospect business partner. When one's counterpart refers to a previously arranged condition, one may ask oneself: "Was I informed of it? How much did I know about it? How much does it bear on current negotiation?" Or when one's counterpart proposes an initiative, one may consult oneself: "What does it mean by such an initiative? What should I do, ignore, reject, or counteract with a different offer?" These questions 
can direct one back to one's self-experience and develop appropriate responses while being physically present in the social
interaction.

In simultaneous consultation, self-dialogue serves a spontaneous function of directing a particular social interaction with the general view of the self while integrating it into the whole system of self-
experience.

\section{Between the Back and Front Stages in Self-Presentation}

In studying the way individuals present themselves in their daily life, Goffman (1959) identified two dramaturgical concepts: front and back regions. According to Goffman, the front region consists of settings, such as office, furniture, and stage props, and the personal front, such as clothing, racial characteristics, speech patterns, facial expressions, and body gestures. The back region, in contrast, refers to the place that is closed and/or hidden from the audience where "he can drop his front, forego speaking his lines, and step out of character" (Goffman 1959:112).

Self-dialogue mediates between the back and front stages. In the back stage, self-dialogue identifies major parameters of an upcoming front stage performance, explores various ways of presentation, decides on the best possible script for the best possible mode of presentation, and rehearses performance in both content and procedure. For instance, in preparation for a job interview, one would ask oneself "How should I approach each milestone in the whole process? For my formal presentation to the organization, what topic should I take? How long do I present? What questions should I prepare to answer from the audience? In my talk with organizational stakeholders, what strategic mistakes should I avoid? What messages do I want to convey to them regarding my qualifications and commitment? How should I fashion my mannerism given the imbalance of power between me as a powerless job seeker and them as powerful job grantors? Similarly, at the informal gathering with staff, what impression do I want to leave to them, serious, knowledgeable, and dependable or easygoing, humorous, and interesting?"

In the front stage, self-dialogue remains active at the doorway to the back stage. It reads scripts, verifies facts, evaluates other participants and their reaction, reflects on the self and its performance, transports needed materials from the back region, and suggests strategies and tactics for tackling various issues in the front. For example, in a press conference when one faces a crowd of questioning reporters, one would have to consult oneself constantly as well as instantly in fashioning one's response: "Should I say yes to that question? What does it mean if I say no? Is this the question I should use to address my fundamental position? Is this a prime opportunity to clear up some of the public misunderstanding about my lifestyle?" A typical transport of back stage materials into the front stage through selfdialogue is: "Oh, yes, I thought about it beforehand. I now just need to rephrase my thought publicly."

Between the back and front stages, especially after a front stage presentation, self-dialogue cleans up the personal front, reflects on the front stage performance, identifies discrepancies between front stage demands and back stage supplies, and makes recommendations to the self regarding its future back stage preparation for the front stage role-playing activity. For instance, after a business negotiation, one would say to oneself: "Now it is all by myself. Tell me how I did it. Did I do a good job? Did my pre-negotiation preparation target most of the problems encountered in the negotiation process? Did I have any problem in retrieving information from the back stage while performing in the front stage? Did I have a hard time in figuring out something because I obtained no help from the back stage? What did I learn from this experience, particularly in dealing with that negotiator from that company and generally in engaging in a business negotiation?" 


\section{Between the Self and its Different Social Roles}

In studying social roles, Merton (1957) puts forth the concept of role-set and identifies various mitigating factors to reduce role conflicts: differential involvement, self-autonomy amid the competition for power, relative insulation of role activities, stepwise resolution of conflicting demands, mutual social support, and temporary withdrawal. Although role-set refers to the compliment of role relationships among different actors in a given social function, it can be applied to the individual as well: How does one coordinate one's different social roles while responding to one's commanding self?

In this regard, self-dialogue organizes different social roles into a system or a logical set so that one role is in proper perspective with another. At the general level, self-dialogue connects each social role to self-identity: how important it is to one's perceived goal of life, what meaning it expresses for one's personal beliefs and values, what image it creates for one's communal or occupational standing in society, and how significant it contributes to one's whole self-existence. For instance, a doctor in urban America, when he or she joins an international volunteer team to render medical service in developing countries, would wonder what his or her volunteer role means to his or her occupational experience, long-term career development, personal values, lifetime goals, and self-identity. In self-dialogue, he or she may say: "I want to enrich my medical experience; I want to practice my belief in humanitarianism; I want to boost my service reputation; I want to beautify my curriculum vitae; and I want to enhance my self-identity because I can achieve social status, gain professional experience, and improve social image by becoming a service volunteer."

Specifically, self-dialogue provides strategies and tactics to mitigate conflicts among different social roles and between the self and its various role-playing activities. Main strategies and tactics include: division of labor, shifting focus, sharing experience, changing the value judgment, self-criticism, and self-encouragement. By division of labor, time and energy are rationally appropriated to different roles or different activities in a role: "How much time do I use respectively for my work, family life, and hobby? In my work as a researcher, how much time do I spend respectively on data collection, data analysis, and report writing?" Shifting focus is to develop a habit of smoothly changing among different social roles while concentrating on one thing at a time: "I, as a doctor, can see patients during my office hours. I can lie down in bed as a patient when I am sick myself. I can read with my children when I am home in the night ..."; "I am exhausted working in this capacity. I need to do something else"; and "I cannot think about my family vacation in the middle of a work project." Sharing experience is to draw upon one social role playing activity for the benefit of another: "I was a student before and know now as a professor that students always like their instructor being clear and fair on class requirements"; "I am a part-time salesperson at a department store but do not fully understand until this moment as a patient how people in need of service expect to be well treated by their service providers"; and "I am the mother of two children and can empathize with my clients when I counsel them on child discipline." Changing the value judgment is to reassess a social role or a role playing activity, especially after some unexpected results: "I underestimated the importance of my role as a mediator in this conflict. I think I need to do more"; and "I took my athlete role too seriously. I now realize that I can benefit myself more in the long run by focusing more on my student role." Finally, self-criticism or selfencouragement comes after failure, fatigue, resistance, and unfavorable social reactions set in a social role or role playing activity: "I am a well-respected police officer. How could I act so angrily and unprofessionally toward those juveniles"; "I always want to be a lawyer. I cannot give up just because of my first-time failure on the bar examination"; and "I have done a decent job in this position overall. This incident is just accidental. I believe I will do better." 


\section{Between the Meaning and its Multiple Expressions}

The meaning of an expression is created and understood through indication and interpretation. In the process of indication, selfdialogue verifies the intent of the self, examines situational factors, and explores different modes of expression: effective, economical, implicit, straightforward, or ambiguous. Suppose one needs help for one's work. In self-dialogue, one would identify appropriate sources of help and figure out proper indications of intent accordingly: "How do I approach them for help? To A, my friend and colleague, I may just say I need help. To B, my supervisor, I cannot just say I need help but have to explain a great deal of my difficult circumstance. To C, I think I have to tell a long story of something else. I must also make some allusion to my planned compensation for his or her help."

In the process of interpretation, self-dialogue analyzes observational cues and clues, assumes the position of others, and decides on the meaning of an expression in various dimensions: directly versus indirectly, in form versus in content, and on the surface versus in essence. Suppose a colleague always smiles and keeps "thanks" in his or her mouth. In self-dialogue, one would attempt to figure out what his or her mannerism means: "I am impressed but feel a little overwhelmed. Is this he or she? Does he or she just act out that way? I suspect he or she uses his or her mannerism as a strategy of impression management or a mechanism of self-defense? Am I right?"

The indication and interpretation of one meaning, one thing, and one self in multiple expressions make human communications creative, colorful, and interesting as well as tricky, challenging, and problematic. As the mental connection between the meaning and its multiple expressions, self-dialogue explores different modes of indication and interpretation and therefore facilitates interpersonal interactions across social groupings. It also causes problems in social life with unintended indications and misinterpretation. However, when misunderstanding occurs, can it be overcome only through more active and creative self-dialogue.

\section{Between What is Said and What is Meant}

Oral expressions are made primarily with linguistic utterances. Spoken words and sentences are guided by the existing rules of language. A particular word, phrase, sentence, or other linguistic element is attached with a specific set of meanings. The meaning-set of a given utterance may be definite in size. But the size of any individual meaning-set can vary from one to two to any number of meanings. For instance, the meaning-set of "no" may contain fifty different meanings while that of "good" may have only a dozen.

Self-dialogue makes a distinction between what is said and what is meant as it creates meanings for words and sentences. From a macropoint of view, words and sentences develop their meanings through use in social interactions. From a micro-point of view, however, new meanings are created when self-dialogue attempts different indications and interpretations with existing words, sentences, and other linguistic elements. For example, a new meaning may have been added to the meaning-set of "thanks" in the following self-dialogue: "I had nothing else to say except uttering an unwilling 'thanks.' I think he understood what I meant."

Self-dialogue connects what is said to what is meant when it indicates a meaning to the knowledge of the self as well as to the attention of an audience. To indicate a meaning, self-dialogue first informs the self: "When I said 'It is fine,' I did not mean the matter under consideration is fine. I just wanted to move his attention away." It then conveys the meaning to the audience through a specific combination of facial expression, tone, gesture, and other body movement. Following one's evasive reply "It is fine," one would have to talk something else, walk away, or ask a counter-question, such as "Are you Okay with your new girlfriend?"

Similarly, on the part of the audience, self-dialogue figures out the meaning of a message in relation to the context in which it is received. One would not take "Thanks" simply as it is uttered. 
Nor would one interpret "It is fine" as it is claimed. Instead, one would engage in self-dialogue to first capture the intended meaning of "Thanks" or "It is fine," and then assess the different degree in which the intended meaning is expressed. Suppose one receives an invitation from a colleague of the opposite sex to play a tennis game. In self-dialogue, one would wonder: "This does not sound as a simple invitation to a tennis game. Is it an expression of collegiality, a suggestion of affection, or a prelude to some business dealings? Assume it is simply about collegiality. How much collegiality is it expressed? How much appreciation do I need to show in my response?"

\section{General Coordination, Management, and Integration}

An individual plays different social roles in numerous social occasions. How do pieces of social encounters stick together to make a whole social experience? How do different social roles converge to form a general social image? How is the general social image perceived by the self? How is it related to self-identity?

At a general level, self-dialogue engages in coordination, management, and integration, making meaningful distinctions as well as connections between "I" and "me," between the whole self-existence and fragmented social experience, between self-identity and social image. By coordination, self-dialogue maintains the channel of communications between "I" and "me," promotes the sharing of information among different role-playing activities, and achieves consistency, harmony, and unity within the self. For instance, selfdialogue coordinates social image with self-identity by passing demands, collecting feedback, and matching offers from each other. A strong sense of communal values and family responsibility derived from self-identity may dictate a perceived social image of a caring father or mother and a loving husband or wife: "I am a family man. I want to take good care of my family. I send my children to school every morning and come home for dinner every evening no matter how busy I am with my work. In the weekend, I stay with my family at home, in parks and church, or take them on excursions. I would be surprised if any of my neighbors, colleagues, friends, or relatives ever questions my commitment to family." Similarly, a perceived social image of a model parent or spouse may require a desired quality, confidence, and pride in self-identity: "I am one of those old-fashioned parents in the eyes of my neighbors, co-workers, friends, and relatives. Over these years, I did what I always want to do: be a caring father and a loving husband. I am a through and through family person."

In management, self-dialogue identifies problems, develops solutions, and takes precaution for emergencies. The self is an active force of creativity and innovation. It bears an inherent desire for freedom, multiplicity, and change. Between "I" and "me," "I" aspires to attain self-actualization through different "me" or a variety of social images while "me" is motivated to enrich "I" or the whole self-existence in an array of social encounters. "I" may want to be a nice, easy-going, and interesting "me" in one occasion and a tough, rigid, and stubborn "me" in another. "I" may also have to act in different capacities simultaneously at work or play different roles uninterruptedly in life. Creative impulses from the self and realistic constraints in society can combine to cause various conflicts, problems, emergencies, and crises in one's self-existence, calling for proper measures, strategies, and solutions. For example, when "I" questions "me" for an unexpected social image in the making, one would have to engage in self-dialogue for a management resolution: "I am a liberal intellectual. I do not want to police my class too much. I want to give my students as much freedom as possible. But after a few weeks of practice, I find that some students are taking advantage of my liberal approach: they do not come to the class and talk to each other during my lecture. I feel that a negative image of ' $m e$ ' is in the making among the class. What should I do? Should I change myself and ground unruly students in class? No, that's not 'I,' or the kind of 'me' I want to have in the eyes of my students. I simply cannot do it. Then what? I should be firm and 
tough on class requirements. It will show that I am not weakly willed. Also, being tough on class requirements will teach the class what it means by having a maximum amount of freedom in the process of learning."

Through integration, self-dialogue bridges the temporary with the permanent, episodes with the story, and parts with the whole. There are two processes of integration: deduction and induction. Deduction is to draw upon the general system of self-existence for undertaking a specific social interaction. Induction is to generalize from particular social interactions to enrich the ever-evolving universal system of self-identity. Suppose one experiences a serious betrayal by a seemingly trustworthy colleague. Self-dialogue would sort out facts from an initial uproar of anger and make general notes for future reference. First, one would ask: "Why did I trust the person and share all my secrets with him or her?" Second, one would wonder: "What kind of person is he or she?" Third, one would wrap it up with some reflections: "What did I learn from this incident, about that person and that kind of persons in particular, and about interpersonal relationship, trust, and betrayal in general?"

In general, self-dialogue creates gaps, confusions, and problems, but also bridges gaps, clarifies confusions, and solves problems. It is a force of innovation and productivity as well as a source of misunderstanding and intellectual squandering. Reflecting upon the amount of time and energy one as an average person spends on self-dialogue, one may well wonder: Is it an unnecessary waste of my intelligence or a useful exercise of our human wisdom?

\section{RULES AND REGULATIONS}

Self-dialogue occurs within the sphere of the self and remains apparently free from any formal social sanctions. Is it therefore an "anything goes" process? Or is it still subject to some regulations? If it is a regulated process, what rules does it follow?

\section{Ontological Limits}

Self-dialogue floats in consciousness. Consciousness acts upon mind. Mind lodges in body. Body and mind combine to constitute the human existence. Self-dialogue, in this sequence, is subject to the various ontological limits imposed by the nature on the human species. At the outset, self-dialogue cannot go beyond the sphere of consciousness nor can it function properly without the logistical support of the body. By its nature, self-dialogue does not promote conflict within the self, nor does it upset the mental flow of consciousness, pit mind against body, and disrupt order in selfexperience. Instead, it works to resolve contradictions within the self, facilitate mental activities in consciousness, reconcile mind with body, and maintain peace in self-existence. For instance, self-dialogue does not normally engage in constant self-denial and self-destruction to the detriment of self-existence although it may conduct selfevaluation, self-criticism, and self-modification for the functional purpose of self-betterment.

\section{Logic and Linguistic Rules}

Self-dialogue falls under the law of logic. It distinguishes things from one another by time and occurrence: "I answered this question before. Why does he ask the same question now?" It compares objects to each other in terms of size and distance: "Because I am so much taller, I have to maintain a proper distance from my boss when I talk to him." Differences in extension and intension are conceived: "I think loyalty means honesty, dedication, and commitment. My loyalty to my friends manifests in various things I do with them: telling truth, sharing pain and pleasure, taking care of each other, spending time together, and devoting energy to the relationship." Contrasts in scope, content, importance, power, and status are comprehended as well: "I as a university professor understand that teaching is valued because it contributes to individual growth and that research is more valued because it contributes to human progress in general." 
As far as linguistic rules are concerned, self-dialogue must make sense to and be understood by the self. Just as "I" watches news, reads books, and listens to somebody else, "I" follows the same linguistic conventions to communicate with "me" in self-dialogue. Nouns designate things. Pronouns represent people. Adjectives modify people or condition things. Verbs connect people to people, things to things, or people to things. Adverbs modify connections and actions among people and things. The linguistic consistence and coherence from social communications to selfdialogue are illustrated in diaries, where one puts one's selfdialogue in words, following all the rules developed in written language. They are also demonstrated in self-utterance, where one speaks one's self-dialogue, connecting the uttering "I" to the listening "me" as if they are two entities in daily communications. Even in self-speechlessness, where self-dialogue becomes immersed in the stream of consciousness, it is still dictated by what Chomsky (1975) called the deep linguistic structure.

\section{Cultural Norms}

Self-dialogue is conducted in language. Language is an essential part of culture. Through language, self-dialogue follows linguistic rules in form and takes on beliefs, norms, taboos, fear, and other cultural elements in content. Beliefs give one confidence, courage, and support when one faces uncertainty, difficulty, and challenge in one's life: "I am not sure how they will evaluate me. But I think what I am doing is excellent and I have a firm faith in universal justice and fairness." Norms offer one essential references when one decides what is right, good, or positive and what is wrong, bad, or negative: "If I cheat on the exam, I might be able to obtain a promotion. But that is simply wrong. I would see myself as a bad person. It would also leave a negative impact on my career." Taboos institute inhibitions as well as punishments should an inhibition is breached. For example, incest is a taboo. A mental rehearsing of an incestuous act may lead to shame and condemnation in self-dialogue. Finally, fear measures the degree to which the instinct of self-protection is balanced with the motive of self-realization. Self-realization sets goals beyond the status quo and therefore may put oneself under challenge, uncertainty, and anxiety, which in turn can activate one's self-protection mechanism and create a state of fear. While self-dialogue deals with fear in specific situations, fear provides self-dialogue with a basic tone or mood as what is feared and how fear functions for various purposes are essentially related to the general mode of adaptation in a culture.

\section{Social Rules}

Marx (1962), in questioning the free dimension of human thoughts, candidly wrote that most law-abiding citizens could be charged with heinous crimes should mind be policed and held accountable for all possible criminal displays within its boundary. Although he used the scenario to emphasize the deciding importance of acts over thoughts in society, Marx seemed inadvertently to suggest that one may free oneself from social rules in self-dialogue while living in the reality of social restraints. On the other hand, Sykes and Matza (1957) find that one has to develop techniques of neutralization to free oneself from one's learned social rules for any deviant actions. Beginning in selfdialogue, one needs to rationalize one's deviant intent, convince oneself about the necessity and justifiableness of the corresponding act, and come up with a set of neutralizing vocabularies to ward off any possible attack of the social world. The neutralization process affirms that people learn and internalize social rules and that social rules internalized provide guidance and restraint to the inner thinking and reasoning process, including self-dialogue.

What are social rules? How do they regulate self-dialogue? Social rules include formal laws and informal behavioral guidelines. People learn social rules through socialization and re-socialization. Adherence to social rules can be voluntary and involuntary. Penalty for breaking or failing to follow social rules can range from imprisonment, fine, reprimand, and shame, to a loss of face. Self-dialogue takes place within the consciousness of one's social experience. How it is regulated by one's internalized social rules corresponds to how one is guided and restrained by existing laws, mores, and folkways 
in one's society. The difference is: What one does in one's society leads to social reactions whereas what one imagines in one's selfdialogue only triggers warnings. For instance, one will be arrested and punished corporally if one injures somebody in a robbery however, one may only feel a sense of shame when one talks about raping somebody in a series of self-dialogue. The leeway one enjoys in one's self-dialogue in the observance of social rules leads one to two contrasting outcomes. On the one hand, one sees one's self dialogue follow social rules and remain functional to one's social survival as one becomes a productive and law-abiding citizen. On the other hand, one sees one's self-dialogue revolve constantly around the breaking of social rules and become dysfunctional to one's social adaptation as one is cast away from the social mainstream to the negative identity of a deviant, criminal, or rebel.

\section{Proper Regulation}

The function and dysfunction of self-dialogue lead naturally to the issue of its proper regulation. Durkheim (1952), in his study of social integration, pointed out that regulation, when insufficient or excessive, can become a major cause for social problems in general and suicide in particular. Self-dialogue, as driven by free will and regulated by ontological limits, logic, cultural norms, and social rules, can be vulnerable to both insufficient and excessive regulations. What happens when self-dialogue is insufficiently or excessively regulated? First of all, is there a proper regulation of self-dialogue in terms of intensity, rationality in content, frequency of deviance, occurrence of contradiction, and correspondence to social behavior?

The proper regulation signifies a state of balance between the need of expression and the demand of control in consciousness. The level of self-dialogue is moderate: Body is not exhausted, mind is not overstretched, and self-dialogue flows naturally in the service of selfexpression and self-control. The content of self-dialogue is logical and rational. Incidence in self-confusion, self-misunderstanding, and self-loss is kept in minimum. Deviant thoughts occur occasionally but are always confronted and contained by positive norms and rules. Contradiction appears sometimes but self-dialogue overall features an orderly pattern of consistency, coherence, and effectiveness. Most important, self-dialogue corresponds generally to social experience: One does not constantly hide, twist, or separate one's self-dialogue from one's social role playing activities; nor does one always keep two different sets of vocabularies, thinking something in self-dialogue while doing something else in social interactions.

\section{Insufficient Regulation}

In the case of insufficient regulation, one indulges in fantasy. Selfdialogue runs wild and remains burdensome, useless, and dysfunctional to social survivals. Specifically, the level of self-dialogue is high. Mind is spoiled. Body is exploited. The ontological limit is challenged and threatened to its ultimate capacity. An imbalance may be first caused by the use of a substance. But once it is established, one tends to use more substances to fuel self-dialogue in the form of hallucination, delusion, fancy-seeking, and aimless roaming through consciousness. Contents in self-dialogue are mostly irrational and illogical: One attempts to avoid reality and commonsense; one searches for miracle, heavenly comfort, and extraordinary insights; and one always fails with one's attempt and search in the middle of nowhere. Deviance is a constant theme: "How wonderful would it be if I took over that 'neverland' estate?"; "How merry would it be if I had a love affair with that 'blonde' girl?"; and "How peaceful would it be if I got rid of that 'cocky' guy?" Contradictions occur frequently as self-dialogue changes constantly from topic to topic, from mood to mood, and from scene to scene. One becomes excited, frustrated, or scared oftentimes for no reason, aim, and effect: "I feel I have talked a lot of different things to myself this whole day but I am still at loss of where I am." Finally, self-dialogue, as it wanders aimlessly through consciousness, does not correspond closely and meaningfully to social reality and therefore does not serve one well for one's social functioning. In fact, it may drive one away from 
one's social role playing responsibility and predispose one to deviance, mental illness, and criminal activities.

\section{Excessive Regulation}

When self-dialogue is excessively regulated, one feels little space for oneself. Life becomes boring, tiring, pale, suffocating, and nearly meaningless. The level of self-dialogue is low. Mind is numbed with self-instituted fear and taboos. Body is restrained along with the oppressed mind but nevertheless may explode with tremendous power and energy in an externally triggered defensive or offensive action. Rationality is pursued not only as the end but also as the means. Upset by a peccable and fallible reality in self-dialogue, one is rather inclined to retreat to a pure obsession with one's untenable ideal of logic and perfection. The content of self-dialogue is closely censored. Deviant impulses and thoughts are considered as a shame, insult, assault, or crime to personal integrity or some higher spiritual state. A deep sense of guilt is felt if they are not totally suppressed or if the self is not heavily punished when they surface in self-dialogue. Contradiction is not tolerated and is often feared as a taboo. The self is censured and the functional quality of mind is questioned when contradictions occur: "How could I say something opposite in the middle of this argument?"; "What kind of mind do I have?"; and "Am I insane or is this another case of off-mind?" An exact match of self-dialogue to social behavior is demanded in the same line. Mismatch leads to self-condemnation on both moral and functional grounds: "How could I be so dishonest by doing something different than what I say to myself?"; and "Am I incompetent as I fail to realize the goal of accomplishment I promise to myself?” As a result, selfdialogue is often discouraged from its active service as a source of inspiration for social role playing activities.

In general, self-dialogue can be forced into retreat if it is overregulated or run out of control if it suffers from a lack of regulation. Only when it is properly regulated by ontological limits, logic, cultural norms, and social rules, can it maintain a functional level of intensity, exhibit a normal trace of rationality, accommodate certain deviance, tolerate some contradiction, and serve one adequately for one's role playing activities in society.

\section{APPLICATIONS AND IMPLICATIONS}

Self-dialogue is a natural process in human consciousness. It occurs on its own regardless of one's conscientious effort. However, understanding self-dialogue can help one manage it, and knowing how to manage it can help one make beneficial use of it in various aspects of life.

\section{To Speak the Unspeakable}

In its most basic application, self-dialogue serves as a major forum or a fundamental process for self-expression. Living within ontological limits, cultural norms, and social rules, people often find themselves in a situation where they feel they want to say something but cannot say anything at all. The "unspeakable" is therefore coined to characterize such a social condition as well as an individual mental state.

The unspeakable, as conditioned by social situations, may involve different levels of unwillingness, disapproval, and inhibition. At the bottom line is a situation where one does not have to say anything. In other words, it is a speakable but better-to-be unspeakable situation. For instance, when the requirements of a job are written in the book and become known to all employees, the supervisor may not be willing to repeat them in various occasions, and reiteration may also sound collectively disapproving. Then is the situation where one does not want to say anything. There are justifications for speaking it out but it remains unspoken and hence becomes unspeakable because of self-concern or a lack of interest. For instance, one sees someone doing something inappropriate and chooses not to communicate one's observation to him or her because one feels it is not one's 
business or one feels one does not want to be bothered when one oneself does the same. The next situation is where one cannot say anything. It is unspeakable due to social conventions, disapproval, or inhibition. For instance, one does not stop one's boss and demand an apology when he or she tells one about an important task and sprays inadvertently his or her spittle in one's face. Or one cannot utter "Down the Dictator" in the street when one lives under a dictatorship. The subtlest situation is where one is afraid of saying anything. It is more complicated than the situation where one cannot say anything because of social conventions, disapproval, or inhibition. For instance, one does not speak against injustice by the authority because it puts one in danger. Or one does not report one's being raped or robbed because one's life is at stake.

The unspeakable may also occur as an individual mental state. One simply cannot say anything although one feels something clearly and has attempted to speak it out. Even in self-dialogue, one may still wonder: "I have the feeling. I have the insight. I have some intuition. But after all I just cannot say exactly what it is." From a psychoanalytic point of view, the mentally conditioned unspeakable may originate from self-inhibition or suppression instituted by superego (Freud 1963). It may also result from some bodily process, such as physical fatigue and mental blackout.

In essence, all the unspeakable must be spoken in some way. Selfdialogue hence provides a forum where one approaches the unspeakable, analyzes its original meaning, and identifies ways of expressing it. For the socially conditioned unspeakable, one may speak it by the way of lying, implying, alluding, and hinting but it is in selfdialogue where one knows exactly what it is all about and whether one has expressed it in an indirect way. For the mentally caused unspeakable, it is also through self-dialogue that one solves the puzzle and becomes able to speak it to oneself sometime later. Most important, by speaking the unspeakable in self-dialogue, one maintains one's world of reality as well as one's sense of identity, integrity, and morality. For instance, when one chooses not to communicate to one's colleague about his or her inappropriate behavior, one needs to speak it out in self-dialogue to highlight one's mastery of important behavioral standards and maintain one's value system for the future evaluation of oneself and others. Similarly, when one has to take saliva in the face from one's boss, one needs to explain in self-dialogue why one has to tolerate such an unpleasant incident and how one oneself might be a little more sensitive when one is someday in the supervisory position.

It is clear that self-dialogue provides a backstage to speak the socially unspeakable or to straighten out what is indirectly or incompletely spoken in social situations. To the mentally conditioned unspeakable, self-dialogue serves as a front stage for it to be pulled out, deciphered, and understood. Using self-dialogue consciously and skillfully to speak the unspeakable not only fulfils an ontological requirement that all the unspeakable be spoken in some ways but also eliminates a mundane condition for selfconfusion, self-incrimination, and mental illness.

\section{To Cope with Social Stress}

Speaking the unspeakable is an important way to defuse stress. In addition, self-dialogue offers various other ways to cope with stress in social interactions. In performing social tasks, for example, stress may come from stage to stage: How one perceives the task, positions oneself in the group, makes a work plan, performs the task with a proper level of knowledge, skill, and confidence, cooperates with others, and claims one's credit in the joint performance. Self-dialogue can assist one to cope with stress before, during, and after task performance.

Before task performance, stress may take the form of anxiety, nervousness, or low-confidence due to excitement, a lack of interest, unrealistic expectations, or other mental reaction. To defuse stress, one would have to talk to oneself, evaluating one's strengths and 
weaknesses, predicting one's involvement in the task, developing tentative strategies and tactics, and making necessary preparations.

Most stress, of course, appears during task performance when problems erupt, calling for specific and timely solutions on the spot. Self-dialogue first alerts one to the existence, extent, and impact of a problem, paving the way for its identification and possible resolution: "I sense some problems there. What am I going to do?"; "Oh, my gush! I never see this happening. What does it mean? I get to figure it out"; and "It's been tremendous stress to bear with this problem. I wish I could walk out of this mess soon." It then helps one evaluate each problem according to its particular relevance and importance, and advises one what to do, what not to do, and how to execute a finalized plan in the process of task performance.

After task performance, one would have to reflect on what has been achieved or unaccomplished, what proves to be effective or ineffective, and what to build on for the future. Stress may arise or worsen if failure or success is not properly recorded. Self-dialogue at this stage is therefore to offer reasons or excuses for the finished task, and to search for alternatives to failure or ways of advancement on the basis of success. For instance, after a failed task performance, one might comfort oneself by saying "I did my best. It turned out this way because of uncontrollable factors. I have many more positive things to look forward to in my career."

Obviously, by understanding the nature and functions of self-dialogue in social role-playing activities, one can not only sharpen one's skills for task performance, but also enhance one's effectiveness in stress management.

\section{To Maintain Mental Health}

Speaking the unspeakable and managing stress at work and in life through self-dialogue pave the way for mental health. In a systemic level, however, mental health depends directly on how self-dialogue flows in consciousness in terms of frequency, intensity, rationality, and relevance to reality. As aforementioned, when self-dialogue is over-regulated or suffers from a lack of regulation, it itself becomes a source of mental problems.

How should one conduct one's self-dialogue to maintain one's mental health? Specific guidelines differ for people with different characters and lifestyle experiences. But in general, one should keep one's self-dialogue open all the time and follow two fundamental rules while in self-dialogue: treating oneself courteously as another person and treating oneself with care as oneself.

Treating oneself courteously as another person means that one recognizes and respects the distinction between "I" and " $m e$ " in the process of selfdialogue. One does not assume that it is "my" world so "I" can throw out whatever "I" wants. One does not force anything upon oneself nor expect that "I" will be able to take it in the end. Instead, one takes time and patience to study, entertain, and play with oneself. When it comes to disappointment, regret, and pain, one comforts oneself as a lover. When it comes to joy, success, and pleasure, one enjoys with oneself as a friend. When it comes to dealing with a harsh condition, doing a difficult job, and accepting a tough reality, one negotiates with oneself as a partner. No further step is taken until oneself is understood, convinced, and satisfied.

Treating oneself with care as oneself means that one synchronizes with "T" and "me" in the process of self-dialogue. One develops a sense of "my" world and knows exactly how to reach the most inner corner of one's mind. One maintains a feeling of self-concern, self-care, and selflove, remains sensitive and responsive to what one needs, wants, likes, dislikes, worries, and fears, and is therefore capable of fashioning most appropriate reactions amid different mental states: activity, rest, and silence. For instance, when one faces an important issue in one's life, one may say to oneself: "It is 'my' pain. 'I' feel it. 'I' have to take the best care of myself through this crisis"; "It is 'my' victory. 'T' made it. 'T' am entitled 
to make the best out of it"; and "It is 'my' career that is at stake. 'I' can see it. I will do my best to make it a maximum success."

In general, self-dialogue is both means and ends to mental health. As a means, one uses it to sort out problems, clear up concerns, and maintain space for control and freedom. As an end, one keeps selfdialogue as a state of consciousness. One feels healthy when selfdialogue flows with "I' and "me" in proper separation and combination.

\section{To Achieve Personal Integration}

At a higher level, self-dialogue lays the foundation for personal integration. In their daily life, people play different roles and engage in different activities. Sometimes they are conscientious, honest, and truthful. Sometimes they are out of character, joining in the fun on occasion. There are also times when they lie intentionally or unintentionally. In terms of emotion and mood, people are now optimistic, now pessimistic; now happy, now sad; and now enthusiastic, now dispassionate. Given all these different facades and changes, how does one maintain one's identity and integrity?

First, self-dialogue provides a universe to accommodate different activities in proper perspective. The universe where one positions oneself is not a given mental existence. It becomes available when one thinks and engages in self-dialogue. In the universe, one builds a self-identity and branches it out to different roles. When one focuses on some role playing activity at a particular time and locale, one refers to the general identity for a specific conferment of meanings as well as a proper investment of time and energy. Activities occur in sequence. New elements crystalize into the general identity according to their respective value and importance in self-realization and self-expansion.

Second, self-dialogue provides justifications for why things happen so that the general self-identity is maintained without any serious challenge. It also explains specifically why something is valued or ignored, tolerated or rejected, and encouraged or discouraged. For instance, when one is caught in a controversy and everybody else seems to be confused, one would still have to develop an acceptable version of reality to oneself. This version of reality may be conditioned by some self-conscious yet unspeakable motive, deed, or fact. Its being developed and maintained in one's self-dialogue, however, can help one stick to one's identity as one moves through the crisis.

Third, self-dialogue mediates between the universal and the specific, the general and the particular, the eternal and the temporary, and the essential and the incidental. From the universal, the general, the eternal, and the essential, self-dialogue brings out one's whole identity so that one is not lost in any particular everyday life activity. It also presents the general principle or goal derived from one's identity so that one can pursue its application or realization in one's specific endeavor in the real world. Beginning with the specific, the particular, the temporary, and the incidental, self-dialogue seeks enrichment, expansion, and generalization so that one's identity, principle, and goal can be tested, modified, and elevated. For instance, a scholar reads, speaks, and writes different things in different time and places. But he or she is generally guided, in each particular incident, by a universal scholarly character he or she has developed for him- or herself through numerous specific experiences. In his or her consciousness, it is self-dialogue that mediates between the general and the particular and therefore helps him or her achieve his or her personal integration.

Although it may seem to be a default that self-dialogue speaks the unspeakable, copes with social stress, maintains mental health, and achieves personal integration, one can skillfully manage one's self-dialogue, making it better serve one's needs for a desired level of personal activity, vitality, and achievement. 


\section{Self-Dialogue and Social Conditions}

To a large extent, self-dialogue is a personal adaptation to, and therefore an individual reflection of social conditions and human evolution. As far as human evolution is concerned, a more advanced stage is usually associated with a higher degree of biological, physiological, and psychological complexity and sophistication that may in turn support broader, more intense, and more delicate self-dialogue.

In the social domain, drastic social change may affect the level and intensity of self-dialogue. During the time of economic depression, war, political repression, epidemic, or natural disaster, people may have to engage in more self-dialogue to cope with a harsh reality in their everyday life and understand what happens and why. Fear, uncertainty, and insecurity, if unresolved through self-dialogue, may translate directly into mental illness. For instance, mental disorder is positively correlated with unemployment (Brenner 1973). Birth during the Great Depression leads to a significantly worse psychological state than birth at the later time (Srole 1978).

Specifically in contemporary society, is there a unique level, scope, or intensity of self-dialogue that is shared by the general populace? The modern era features a transition from mechanic solidarity to organic solidarity, from collectivism to individualism, from economic selfsufficiency to mass production, and from autocratic repression to institutional democracy. Social life becomes compartmentalized. Individuals are caught in between specialization required by the division of labor and self-actualization inspired by individualism. Self-dialogue delves in depth to explore the potential of individual freedom and creativity. It expands in breath to capture the scope of social change and human evolution. As reflected in modernist creations, such as arts, music, and architecture, self-dialogue seeks self-expression and self-realization in the outreaching and overarching symbolism of strength, power, and control (Bertens 1995).
Entering postmodern era, people seem to be retreating from outward conquest to inward cultivation. Social life becomes repressive and alienating through endless competition. People feel a great need for reflective space to maintain self-identity and to embrace "plurality, ambiguity, ambivalence, contingency, and uncertainty" (Elliot 1996:4). The level, extent, and intensity of self-dialogue is on the rise under postmodern social conditions. But self-dialogue as a whole no longer seems to necessarily serve the purpose of self-expression and self-realization as under the philosophical inspiration of modernism. Will it then lead to self-containment, self-entrapment, and self-destruction? Will self-dialogue be more reflected in alcoholics, drug abuse, hallucination, the bizarre, the extraordinary, and the extreme than diaries, music, visual arts, and everyday life creations?

\section{CONCLUSION}

In the final analysis, self-dialogue is just a functional equivalent to the human thinking process. The content of self-dialogue is just about human thoughts, imagination, and idealism as partially reflected in arts, literature, and other conceivable social creations. People think and translate their thoughts into products of beauty or utility as long as they live in selfconsciousness. What is the significance then to highlight self-dialogue as a fundamental process of expression or creation?

The answer lies in modern and postmodern social conditions where life is compartmentalized, human relations become impersonalized, and individuals are faced with constant depression, repression, and stress in their economic, political, and social survivals. It is necessary and important to create and maintain a private space for self-identity while living in such a social environment. Self-dialogue arises, in importance and significance, to just meet the needs of individuals to live their modern and postmodern life. First, self-dialogue puts the self on the center stage. Thinking, to a degree, has evolved into a generalized and therefore dehumanized process: you think, they think, everybody thinks, and probably nobody thinks. Self-dialogue, in contrast, offers a focused and 
personalized perspective: "I talk to myself; it is within myself; and it therefore belongs to myself."

Second, self-dialogue carries a sense of caring and sharing that is lacking in modern and postmodern social life. As they are locked into their respective specialty and isolated from each other through social compartmentalization, people have more and more disappointment, frustration, and discomfort to deal with at work and in life. Yet they find less and less time, motivation, and resource for seeking help from the outside. More essentially there are not many places to turn to for personalized assistance. As a result, more and more people feel they have to self-help by establishing a constant dialogue with themselves. Self-dialogue, in this sense, is not only a fundamental process of selfexpression but also a therapeutic procedure of stress management, selfhealing, and self-refueling: "I realize that disappointment, failure, and pain are inevitable elements of my life. I take time to talk about them with myself. I comfort myself on any of my personal discomfort. I keep myself aware of, alert on, and prepared for any possible problem I may
experience in my life."

Third, self-dialogue explores inwardly into the richness of consciousness as well as the complicatedness of the self. In self-dialogue, individuals see the distinction and difference between "I" and "me," between fragmented social experience and the whole self-existence, between back stage maneuvering and front stage playing, and between the speakable and the unspeakable. Reflection deepens upon the working of the self, the nature of social life, and the link of thoughts to actions. Understanding increases in different dimensions of life. For instance, self-dialogue provides beyond-behavior insights into the changing boundary between the speakable and the unspeakable. The speakable is not just a behavioral utterance that is socially appropriate and meaningful. It is a social realization of what is meant to be speakable in self-dialogue. Likewise, the unspeakable is not just what is unsaid in social contexts. It is a mental reservation of what is meant to be unspeakable in self-dialogue. Most interestingly, the unspeakable is usually spoken and becomes speakable in self-dialogue whereas the speakable often remains unspoken and becomes unspeakable in social contexts.

It is the rise of self-dialogue out of the general thinking process that prompts its study by the academician and its use by the layman. The significance of self-dialogue in modern and postmodern life, however, has yet to be unfolded and understood. At the individual level, is selfdialogue a self-retreat from realistic social life? Is it an awakening revolution of self-identity? Or is it a prelude to the total emancipation of the self? At the social level, is self-dialogue an indication of the decline of "social" life? Is it a mode of human adaptation to competition, division of labor, and compartmentalization of life? Or is it an evolutionary development for human beings to master their social life in its wholeness? Between individuals and society, are mind, thoughts, and idealism ahead of, synchronous with, or behind body, actions, and realism? Does selfdialogue serve to strengthen mind and thoughts for the breadth, depth, and intensity of modern and postmodern social life? Or does it serve to prepare mind and thoughts for an ever challenging society yet to come? All these questions remain open for further exploration.

\section{REFERENCES}

Allport, Gordon W. 1937. Personality: A Psychological Interpretation. New York: Holt.

Bamberg, Michael. 1997. "A Constructivist Approach to Narrative Development.” Pp. 89-132 in Narrative Development: Six Approaches, edited by Michael Bamberg. Mahwah, NJ: Lawrence Erlbaum.

Barker, L. and R. Kibler. 1971. Speech Communication Behavior: Perspectives and Principles. Englewood Cliffs, NJ: Prentice-Hall.

Bakhtin, Mikhail. 1984. Problems of Dostoevsky's Poetics, edited and translated by Caryl Emerson. Minneapolis: University of Minnesota Press.

Bertens, Hans. 1995. The Idea of the Postmodern: A History. New York: Routledge.

Bielby, Denise D. and Hannah S. Kully. 1989. "Social Construction of the Past: Autobiography and the Theory of G. H. Mead." Current Perspectives on Aging and the Life Cycle 3: 1-24. 
Blumer, H. 1969. Symbolic Interactionism: Perspective and Method. Englewood-Cliffs, NJ: Prentice-Hall.

Brenner, M. Harvey. 1973. Mental Illness and the Economy. Cambridge, MA: Harvard University Press.

Bruner, Jerome. 1987. "Life as Narrative." Social Research 54 (1): 11-32.

Butler, P.E. 1992. Talking to Yourself:Learning the Language of Self-Affirmation. San Francisco: Harper and Row.

Chomsky, Noam. 1975. Reflections on Language. New York: Pantheon.

Comte, Auguste. 1970. Introduction to Positize Pbilosophy. Indianapolis, IN: BobbsMerrill.

Cooper, David Edward. 1996. World Philosophies: An Historical Introduction. Cambridge, MA: Blackwell.

Durkheim, Emile. 1952. Suicide, translated by John A. Spaulding and George Simpson. New York: Free Press.

Elliot, Anthony. 1996. Subject to Ourselves: Social Theory, Psychoanalysis, and Postmodernity. Cambridge, UK: Polity Press.

Flavell, J. H. 1987. "Speculations about the Nature and Development of Metacognition." In Metacognition, Motivation, and Understanding, edited by F. E. Weinert and R. H. Kluwe. Hillsdale, NJ: Erlbaum.

Ford, Terry L. 1996. "Becoming Multicultural: A Recursive Process of Selfand Social Construction." Theory into Practice 35 (4):232-38.

Fox, Nicholas J. 1994. Postmodernism, Sociology, and Health. Toronto: University of Toronto Press.

Freud, Sigmund. 1962. The Ego and the Id. New York: Norton.

Freud, Sigmund. 1963. An Outline of Psychoanalysis. Translated by James Strachey. New York: W. W. Norton.

Fromm, Erich. 1947. Man for Himself. New York: Rinehart.

Goffman, Erving. 1959. The Presentation of Self in Everyday Life. Garden City, NY:Doubleday.

Gordon, Chad and Kenneth J. Gergen. 1968. The Self in Social Interaction. New York: John Wiley.

Helmstetter, S. 1986. What to Say When You Talk to Yourself. New York: Simon and Schuster.

Hermans, Hubert J. M. 1993. "Imaginal Dialogue in the Self: Theory and Method." Journal of Personality 61 (2):207-36.

Hoelter, Jon W. 1983. "The Effects of Role-Evaluation and Commitment on Identity Salience." Social Psychology Quarterly 46:140-47.

James, William. 1890. Principles of Psychology. Vol. 2. New York: Holt.

Lecky, P. 1945. Self-Consistency: A Theory of Personality. New York: Island.
Lichtenstein, Tovah and Rutie Baruch. 1996. "I Was Born from the Earth': Reconstructing the Adoption Self-Narrative in the Treatment of a Preadolescent Girl." Families in Society 77 (2): 90-97.

Manning, Brenda H. 1990. "Self-Talk and Learning." Teaching K-8: April, 56-58.

Manning, Brenda H. and Beverly D. Payne. 1995. Self-Talk for Teachers and Students. Boston: Allyn and Bacon.

Marx, Karl and Friedrich Engels. 1958. Selected Works. Moscow: Foreign Languages Publishing House.

Marx, Karl and Friedrich Engels. 1962. Selected Works. London: Lawrence and Wishart.

Mead, George H. 1934. Mind, Self and Society. Chicago: University of Chicago Press.

Merton, Robert K. 1957. "The Role-Set: Problems in Sociological Theory." British Joumal of Sociology 8:106-20.

Nichols, Lawrence T. 2000. "Dialogical Constructionism: Toward Holistic Understanding of Social Problems Discourse." Perspectives on Social Problems 12: 55-65.

Park, Robert E. 1928. "Human Migration and the Marginal Man." American Journal of Sociology 33:881-93.

Parsons, Talcott. 1951. The Social System. Glencoe, IL: Free Press.

Parsons, T and E. L. Shils. 1951. Toward A General Theory of Action. New York: Harper and Row.

Polkinghorne, Donald E. and Michael Bamberg. 1991. "Narrative and Self-Concept." Journal of Narrative and Life History 1 (2-3): 135-153.

Polletta, Francesca. 1998. “'It Was Like A Fever ...': Narrative Identity in Social Protest." Social Problems 45 (2): 137-159.

Riches, Gordon and Pamela Dawson. 1996. "'An Intimate Loneliness': Evaluating the Impact of a Child's Death on Parental Self-Identity and Marital Relationships." Journal of Family Therapy 18 (1): 1-22.

Riesman, David. 1950. The Lonely Crowd: A Study of Changing American Character. New Haven, CT: Yale University Press.

Riessman, Catherine K. 1993. Narrative Analysis. Thousand Oaks, CA: Sage Publications.

Rogers, Carl R. 1951. Client-Centered Therapy: Its Current Practice, Implications, and Theory. Boston: Houghton Mifflin.

Rogers, Carl R. 1959. "A Theory of Therapy and Interpersonal Relationships as Developed in the Client-Centered Framework." Pp. 221-35 in Psychology: A Study of A Science, edited by S. Koch. New York: McGrawHill. 
Rosenberg, Morris. 1979. Conceiving the Self. New York: Basic Books. Sarton, George. 1952. A History of Science. Cambridge, MA: Harvard University Press.

Scheff, Thomas J. 1995. "Self-Defense against Verbal Assault: Shame, Anger, and the Social Bond." Family Process 34 (3):271-86.

Seale, Clive. 1995. "Heroic Death." Sociology 29 (4): 597-613.

Skinner, B. F. 1953. Science and Human Behavior. New York: MacMillan. Sokefeld, Martin. 2001. "Reconsidering Identity." ANTHROPOS 96 (2):
527-544.

Somers, Margaret. 1994. "The Narrative Construction of Identity: A Relational and Network Approach." Theory and Society 23 (5): 605-649.

Somers, Margaret and Gloria Gibson. 1994. "Reclaiming the Epistemological "Other': Narrative and the Social Construction of Identity." Pp. 37-99 in Social Theory and the Politico of Identity, edited by CraigJ. Calhoun. Oxford Blackwell.

Srole, Leo. 1978. Mental Health in the Metropolis: The Midtoren Manbattan Study. New York: Harper and Row.

Stapleton, Karyn. 2000. "In Search of the Self: Feminism, Postmodernism and Identity." Feminism and Psychology 10 (4): 463-469.

Steinberg, Marc W. 1999. "The Talk and Back Talk of Collective Action: A Dialogic Analysis of Repertoires of Discourse among NineteenthCentury English Cotton Spinners." American Journal of Sociology 105
(3):736-80.

Stonequist, E. V. 1937. The Marginal Man. New York: Russell and Russell. Stryker, Sheldon. 1989. "Further Developments in Identity Theory: Singularity versus Multiplicity of Self." Pp. 35-57 in Sociological Theories in Progress: New Formulations, edited by Joseph Berger, Morris Zelditch, Jr., and Bo Anderson. Newbury Park, CA: Sage Publications.

Sykes, Gresham M. and David Matza. 1957. "Techniques of Neutralization: A Theory of Delinquency." American Sociological Review 22:66470.

Volosinov, V. N. 1973. Marxism and the Pbilosophy of Language. Translated by L. Matejka and I. R. Titunik. New York: Seminar Press.

Volosinov, V.N. 1987. Freudianism: A Critical Sketch. Translated by I. R. Titunik Bloomington: Indiana University Press.

\section{ANTI-JEWISH PREJUDICE IN CONTEMPORARY Hungary: A SOCIO- Psychological Causal Model}

\author{
BOJAN TODOSIJEVIC AND ZsOLt ENYEDI \\ Central European Unizersity
}

Social Thought E Research, 2002, Vol. 24, 1\&2

Abstract

\begin{abstract}
Predictions from three general approaches toprejudice-personality, social learning and group-conflict-have been examined on a sample of Hun. garian youth and theirparents. The sample consisted of 400 randomly selected collegestudents and their parents from twe Humgarian cities (total $N=800$ ). Thequestionnaireincluded, among others, an antisemitism scale, autboritarianism scale, and sociodemographic variables. Socio-psyy hologicalcausal model reas constructed using unizariate recursize regression graph methodology. The results indicated that students' antisemitism is directly related only topersonality(authoritarianism) and toparents'antisemitism. Students' authoritarianism is related to parents' authoritarianism and familysocioeconomic status as indicated by parents' incomeandeducation). Parents'antisemitism is related to theirowen autboritarian tenden. cies and income, while parents' aut thoritarianism is primarily related to theireducational background. It is concluded that the resultsprimarily support personality approach to prejudiceass represented by Adornoet al.' work (1950), and socialization approach. Group-conflict approach receized ambiguous support in the same way as predictions from this approach conceming individual differencesin prejudiceareambiguous.
\end{abstract}

Key words: antisemitism, prejudice, authoritarianism, socialization.

\section{Introduction}

The roots of modern antisemitism can be traced to the anti-Judaism of the Hellenistic era (cf. Wistrich 1991) and in the identity of early and medieval Christianity (Fein, 1987). But its present form was shaped 